Forum

\title{
Bats are not birds and other problems with Sovacool's (2009) analysis of animal fatalities due to electricity generation
}

\author{
Craig K.R. Willis ${ }^{\mathrm{a}, *}$, Robert M.R. Barclay ${ }^{\mathrm{b}}$, Justin G. Boyles ${ }^{\mathrm{c}}$, R. Mark Brigham ${ }^{\mathrm{d}}$, Virgil Brack Jr. ${ }^{\mathrm{e}}$, \\ David L. Waldien ${ }^{\mathrm{f}}$, Jonathan Reichard ${ }^{\mathrm{g}}$ \\ a Department of Biology and Centre for Forest Interdisciplinary Research, University of Winnipeg, Winnipeg, MB, Canada R3B 2E9 \\ ${ }^{\mathrm{b}}$ Department of Biological Sciences, University of Calgary, Calgary, AB, Canada T2N 1N4 \\ ${ }^{\mathrm{c}}$ Department of Zoology and Entomology, University of Pretoria, Pretoria 0002, South Africa. \\ ${ }^{\mathrm{d}}$ Department of Biology, University of Regina, Regina, SK, Canada S4S OA2 \\ environmental Solutions and Innovations, Inc. 781 Neeb Road, Cincinnati, OH 45233, USA \\ ${ }^{\mathrm{f}}$ Bat Conservation International, P.O. Box 1621603, Austin, TX 78716, USA \\ ${ }^{\mathrm{g}}$ Center for Ecology and Conservation Biology, Biology Department, Boston University, Boston, MA 02215, USA
}

\section{A R T I C L E I N F O}

Article history:

Received 6 August 2009

Accepted 13 August 2009

\section{Keywords:}

Bats

Birds

Wind energy

Recently Sovacool (2009) set out to compare North American bird (avian) and, presumably bat (chiropteran) mortality resulting from three methods of electricity generation, an objective we applaud. However, we feel it is important to point out serious errors in biological fact, logic, and data selection in his paper.

\section{Bats are not birds}

While the word "bats" is prominent in the title of Sovacool's paper, the text is virtually devoid of data on bats. Indeed, Sovacool seems to think that bats are birds despite the fact that the word avian refers exclusively to birds. In one case the author refers to "bats, birds and other avian species" and in another to "[t]hose studying avian mortality..." as a segue into a discussion of research on bats. Birds and bats are unique among extant vertebrates in their capacity for powered flight but bats are mammals (Class Mammalia; Order Chiroptera) with millions of years of evolutionary isolation from birds (Class Aves) and a vastly different biology. Moreover, North American bats occupy an entirely different ecological niche than almost all birds as the

DOI of original article: 10.1016/j.enpol.2009.02.011

* Corresponding author. Tel.: +204783 2842; fax: +204774 2401

E-mail address: c.willis@uwinnipeg.ca (C.K. Willis). primary consumers of night flying insects. While the distinction may seem like a taxonomic nitpick relevant only to biologists, it is central to the conservation and policy issues in the paper. It has become increasingly clear that, in general, mortality at wind turbines is much more a bat issue than a bird issue (Barclay et al., 2007) and it is bats that face the most widespread and worrisome species-level conservation consequences from wind turbines. This reflects differences in the biology of these two different classes of vertebrates, and their patterns of mortality at wind plants. For example, bats investigate wind turbines while birds do not (Horn et al., 2008), migrating bats appear to be attracted to turbines (potentially from long distances) while there is little evidence that birds are attracted (Cryan, 2008; Cryan and Brown, 2007), and bats are prone to depressurization injuries (i.e., barotraumas) at turbines, to which birds are less susceptible (Baerwald et al., 2008).

Another difference between birds and bats is our understanding of their baseline population sizes. Population sizes of bats are poorly understood compared to birds because bats are less-studied and are more difficult to enumerate. Wind turbines represent a new and unprecedented source of mortality that could affect bat populations quickly, before we know how many (or how few) bats there were to start with. This is compounded by the fact that turbines affect a small number of bat species disproportionately. Sovacool's analyses lump together combined impacts on many species of birds and bats, into a single number, "bird deaths per GWh". Including bats with birds is 
highly misleading because, in contrast to the many tens of species of birds incorporated into each of the author's mortality estimates, wind turbine mortality of bats in North America is restricted primarily to three species, the so-called migratory tree bats. Numbers of bats killed per species are much higher for these bats than for birds and, therefore, species-level conservation implications are much greater for bats. In other words, Sovacool's rate of " 0.4 birds/GWh" must be divided among many tens of bird species while the same fatality rate for bats would be divided mostly among three species. Bats also have much slower life histories than birds of comparable size, exhibiting lifespans of up to 35 years in the wild and low reproductive rates of typically one or two young per year (Barclay and Harder, 2003). Therefore, bats are more susceptible than birds to novel sources of mortality. Sovacool's failure to recognize, much less account for these differences, while arguing that his conclusions are relevant to bats, is a serious error.

\section{Erroneous fatality estimates}

Even more worrisome than mistaking bats for birds, Sovacool's (2009) estimate of the average number of birds killed per GWh of wind power is incorrect and omits a large body of easily accessible, published data. For five of the six sites listed in his Table 2, Sovacool used fatality estimates that were uncorrected for searcher efficiency and scavenger losses, despite the fact that corrected data are available. Surprisingly, he then points out that failure to correct for searcher efficiency and scavenging is a flaw in published mortality surveys. Using corrected estimates (Barclay et al., 2007 and references therein), and Sovacool's estimated capacity factor (33\%), the actual estimated number of birds killed at those 6 sites is $0.653 / \mathrm{GWh}$, more than double Sovacool's estimate of $0.269 / \mathrm{GWh}$. Using all 21 sites for which data are presented in Barclay et al. (2007), the average number of birds killed is $1.46 / \mathrm{GWh}$, or over five times Sovacool's estimate. Sovacool also failed to use the same dataset to estimate the rate of bat mortalities. Using the 6 sites in Sovacool's paper, the estimated average number of bats killed is 3.25/GWh, although that number is influenced by the high fatality rate at the Mountaineer site in West Virginia. At all 21 sites for which data are available (Barclay et al., 2007), the average number of bats killed is $1.48 / G W h$. This gives a total fatality rate for birds and bats of $2.94 / \mathrm{GWh}$, or more than 10 times Sovacool's value.

Other smaller but still serious problems abound in Sovacool's comparison of mortality estimates including, for example, failing to account for mortality due to transmission lines for wind power but including this source of mortality for fossil fuels. Wind energy facilities also require transmission lines. He also estimates habitat loss resulting from fossil fuel extraction as a source of mortality while ignoring the potential for habitat loss associated with wind turbines, particularly the large number of turbines required to produce an amount of energy equivalent to that generated by fossil fuels.

\section{Other errors of fact}

Another serious error in the paper, which may result from equating bats with birds, is the statement: "Death rates of all flying animals [from wind turbines] have decreased in recent years". This statement may be true for birds, although the author cites no evidence for it, but the opposite is true for bats. There is clear evidence that, as turbines have become taller, bat mortality has increased (Barclay et al., 2007). In the same paragraph, the author implies that pre-construction monitoring and mitigation reduce the risk of mortality for birds and bats which, again, is simply not true for bats. There is currently no published evidence (or un-published evidence of which we are aware) that any preconstruction monitoring approach has effectively reduced postconstruction bat mortality. When discussing limitations of existing mortality studies at wind plants, the author implies that correcting for searcher efficiency and scavenging might result in either an overestimate or underestimate of mortality (i.e., "having to correct values up or down"). In reality, these sources of error in turbine surveys always result in an underestimate of mortality, especially when searcher efficiencies are low or scavenging rates are high. For example, if some bats are killed on a given night but none are found, these values remain zero in a survey dataset, even after corrections are applied (Smallwood, 2007). Thus, unless searcher efficiency is $100 \%$ and no animals are scavenged, all reported estimates of bird and bat fatality actually underestimate mortality, an important point that is trivialized by Sovacool.

Also worrisome is a fundamental element of Sovacool's argument that among the "600 studies, articles, and reports on avian deaths and wind farms" he surveyed, "not one of the studies examined produced an estimate of how many birds die from wind electricity correlated with the amount of electricity those wind turbines actually generated". In fact, those types of fatality estimates are regularly reported for bats and are occasionally reported for birds. The Kunz et al.'s (2007a) paper cited by Sovacool included both bird and bat fatality estimates reported as "fatalities per megawatt of energy produced per year". The values used by Sovacool from this paper were from a table showing only fatality rates from sites where indices of acoustic activity were also available and, thus, represent a limited sample; those also happened to be the only fatality rates reported in the paper as bats/turbine/yr rather than bats/MW/yr. Further, it is surprising that Sovacool reviewed over 600 sources but failed to reference what we consider the primary literature on bat fatalities at wind turbines (e.g., Arnett et al., 2008; Barclay et al., 2007; Kunz et al., 2007b). All three of these papers report bat fatalities/MW/ year, and all are more readily accessible than the gray literature cited by Sovacool.

\section{The forest or the trees?}

The problems cited above are serious errors of fact, but a major conceptual and potentially more serious problem also plagues Sovacool's analysis. In a clear case of missing important details of the trees to summarize the forest, Sovacool advocates averaging data (i.e., mortality rates) across many species, large areas, and long time periods to estimate the total number of animals killed by the three different electricity systems. This approach fails to address the importance of spatial (i.e., geographic) and temporal variation when contextualizing the conservation implications of different electricity systems. Understanding variation among species, sites and times is essential for a meaningful comparison. For example, Sovacool estimated mortality of "birds" from coal mining from one study on one species in four states. Aside from the fact that dozens of other bird species were likely affected and thus the total number of bird deaths is severely underestimated, geographic variation in species' diversity and abundance render some conclusion for the entire continent meaningless, regardless of whether the author calls it preliminary. Similarly, the majority of migratory tree bats are killed by wind turbines during their fall migration (in general a 6-8 week span between late July and late September; Cryan and Brown, 2007; Cryan, 2008) and the bats appear to travel along specific migration corridors (Baerwald and Barclay, 2009). A relatively small number of wind facilities in specific regions would thus exert disproportionate influence on continent-wide population stability because a large proportion of 
the continent's tree bats are likely concentrated at these sites. Lumping values from these locations, where mortality rates are high, with values from wind facilities sited in areas less critical for migration will clearly underestimate the biological significance of wind energy mortality for populations and species. In contrast, mortality from at least some aspects of fossil fuels or nuclear energy is spread over both time and space occurring, as the author points out, at multiple points during "the fuel cycle". Therefore, averaging values from multiple sites and points in the fuel cycle may provide a better (albeit crude) approximation of mortality. We reiterate that the number of species affected is critical. Large numbers of only three or four bat species appear affected by wind turbines while most or all of the 47 North American bat species are likely affected by fossil fuels and climate change to some extent. Therefore, a value of "bats/GWh" is not an equivalent metric to quantify the potential for species extinction or extirpation due to different electricity systems and, as a result Sovacool's analysis compares apples to oranges or "forests to trees". A more nuanced, realistic approach is required.

Although we lack confidence in Sovacool's mortality estimates, we wholeheartedly agree that use of fossil fuels negatively impacts birds and, despite little published information, almost certainly bats as well. We also recognize that fossil-fuel-generated electricity threatens wildlife and ecosystems in general, and that wind energy has important potential as an alternative. We do, however, argue for the necessity of high-quality information about the species in question when making energy policy decisions related to wildlife conservation. Sovacool claims that "many ecologists, biologists, ornithologists, and environmentalists at large have spoken out against wind power on the grounds that it presents too great a risk to avian wildlife". This statement unnecessarily polarizes the issue and misrepresents the intentions of biologists and other stakeholders interested in seeing that wind energy development, and development for other sources of electricity, can proceed in a way that minimizes direct impacts on wildlife, while also addressing the broader environmental impacts of climate change. Despite his admission that the data are scarce and his analysis preliminary, we are concerned that Sovacool's conclusions rest on fundamental errors and could influence energy policy in ways that are counter-productive for the wind energy industry and the conservation of both groups of flying vertebrates: birds as well as bats.

\section{Acknowledgements}

We thank Paul Cryan and Mary Timonin for comments which improved an earlier version of this manuscript.

\section{References}

Arnett, E.B., Brown, W.K., Erickson, W.P., Fiedler, J.K., Hamilton, B.L., Henry, T.H. Jain, A., Johnson, G.D., Kerns, J., Koford, R.R., Nicholson, C.P., O'Connell, T.J., Piorkowski, M.D., Tankersley Jr., R.D., 2008. Patterns of bat fatalities at wind energy facilities in North America. Journal of Wildlife Management 71, 61-78.

Baerwald, E.F., Barclay, R.M.R., 2009. Geographic variation in activity and fatality of migratory bats at wind energy facilities. Journal of Mammalogy. In press.

Baerwald, E., D’Amours, G., Klug, B., Barclay, R.M.R., 2008. Barotrauma is a significant cause of bat fatalities at wind turbines. Current Biology 18, 695696.

Barclay, R.M.R., Harder, L.D., 2003. Life histories of bats: life in the slow lane. In: Kunz, T.H., Fenton, M.B. (Eds.), Bat Ecology. University of Chicago Press, Chicago, pp. 209-253.

Barclay, R.M.R., Baerwald, E.F., Gruver, J.C., 2007. Variation in bat and bird fatalities at wind energy facilities: assessing the effects of rotor size and tower height. Canadian Journal of Zoology 85, 381-387.

Cryan, P.M., 2008. Mating behavior as a possible cause of bat fatalities at wind turbines. Journal of Wildlife Management 72, 845-849.

Cryan, P.M., Brown, A.C., 2007. Migration of bats past a remote island offers clues toward the problem of bat fatalities at wind turbines. Biological Conservation 139, 1-11.

Horn, J.W., Arnett, E.B., Kunz, T.H., 2008. Behavioral responses of bats to operating wind turbines. Journal of Wildlife Management 72, 123-132.

Kunz, T.H., Arnett, E.B., Cooper, B.M., Erickson, W.P., Larkin, R.P., Mabee, T., Morrison, M.L., Strickland, M.D., Szewczak, J.M., 2007a. Assessing impacts of wind-energy development on nocturnally active birds and bats: a guidance document. Journal of Wildlife Management 71, 2449-2486.

Kunz, T.H., Arnett, E.B., Erickson, W.P., Hoar, A.R., Johnson, G.D., Larkin, R.P., Strickland, M.D., Thresher, R.W., Tuttle, M.D., 2007b. Ecological impacts of wind energy development on bats: questions, research needs, and hypotheses. Frontiers in Ecology and the Environment 5, 315-324.

Smallwood, K.S., 2007. Estimating wind turbine-caused bird mortality. Journal of Wildlife Management 71, 2781-2791.

Sovacool, B.K., 2009. Contextualizing avian mortality: a preliminary appraisal of bird and bat fatalities from wind, fossil-fuel and nuclear electricity. Energy Policy 37, 2241-2248 